NASA Technical Memorandum 83777

\title{
Failure Analysis of Plasma-sprayed Thermal Barrier Coatings
}

Christopher C. Berndt

Cleveland State University

Cleveland, Ohio

and

Robert A. Miller

Lewis Research Center

Cleveland, Ohio

Prepared for the

Eleventh International Conference on Metallurgical Coatings sponsored by the American Vacuum Society

San Diego, California, April 9-13, 1984 


\author{
FAILURE ANALYSIS OF PLASMA-SPRAYED THERMAL BARRIER COATINGS' \\ Christopher C. Berndt ${ }^{2}$ and Robert A. Miller \\ National Aeronautics and Space Administration \\ Lewis Research Center \\ Cleveland, Ohio 44135
}

\title{
SUMMARY
}

This work examines thermally induced fallure processes of plasma-sprayed thermal barrier coatings. Cracking processes give rise to nolse which was monitored by acoustic emission (AE) techniques. The sequential fallure of coatings was examined from samples which were thermally cycled. Coatings of yttria-stabilized zirconfa with and without a NiCrAlZr bond coat were plasmasprayed onto $U 700$ alloy rod. In some cases the substrate was intentionally overheated during deposition of the thermal protection system to check how this process variable influenced the AE response of the specimen. In this way a qualitative appraisal of how process variables affect coating integrity could be discerned in terms of cracking behavior. Results from up to seven consecutive thermal cycles are reported here. Coating fallure was observed in all cases. Fallure of the thermal protection system is progressive, since cracking and crack growth has been observed prior to ultimate fallure. Thus catastrophic fallure occurs at some stage when there is a transformation from the microcrack to a macrocrack network.

\section{INTRODUCTION}

Recent work has concentrated on evaluating plasma-sprayed coatings by acoustic emission ( $A E$ ) methods (refs. 1 to 3 ). The major impetus for this thrust has been the need for characterization of coating fallure processes in order to improve coating integrity and performance during service. Much of this work has been summarized (ref. 4). The prior exploratory work produced useful qualitative results; however, quantitative evaluation of cracking processes within plasma-sprayed coatings has not yet been carried out.

One study of relevance to the present work was directed at the quantitative evaluation of fallure processes within coatings. Amplitude distribution analysis (ref. 3) was used to characterize cracking processes of coatings which were subjected to four point bending. An important result was that poorly prepared coatings exhibited higher amplitude signals and that these were characteristic of interfacial fallure.

This paper analyses $A E$ count rates monitored as a function of temperature in slowly heated and cooled TBC systems. Limitations of this type of experiment are discussed in detail.

TThis research has been supported by the NASA Lewis Research Center under cooperative agreement NCC3-27.

${ }^{2}$ Fellow of the Joint Institute for Aerospace Propulsion and Power, Cleveland State University, Cleveland, Ohio. 
The authors wish to document the technical skills of the late Mr. Jack Brown who prepared the samples used in this work.

\section{EXPERIMENTAL DETAILS}

The experimental equipment used has been described previously (ref. 2). The specimens consisted of $12.7 \mathrm{~mm}$ diameter superalloy rods which were plasma-spray coated over a length of $25 \mathrm{~mm}$ near one end (fig. 1). The coating of $0.4 \mathrm{~mm} \mathrm{ZrO}_{2}-12 \mathrm{wt} \% \mathrm{Y}_{2} \mathrm{O}_{3}$ (YSZ) was sprayed either directly onto the substrate or onto $0.1 \mathrm{~mm}$ of plasma-sprayed $\mathrm{NiCrAlZr}$ bond coat. These coatings are referred to, for convenience, as either single or duplex component coatings. Some poor coatings were also produced by spraying onto substrates which were preheated in excess of the optimum deposition temperature $\left(200^{\circ} \mathrm{C}\right)$ and these are termed as "preheated coatings". The precise degree of preheat is not known and was left to the discretion of the operator. The different sample preparations are referred to as cases $A, B, C$, and $D$. These are distinguished in table I. All specimens were cantilever supported so that they could be inserted into the hot zone of a tubular furnace. All experiments of different coating preparations were carried out in duplicate and the trends observed were similar but not identical.

The $A E$ from the sample was monitored during a heating and cooling cycle that ranged from $55^{\circ}$ to $1200^{\circ} \mathrm{C}$. Only the heating period of the first thermal cycle commenced at ambient temperature due to the high thermal inertia of the furnace. Most noise was emitted on cooling to below $550^{\circ} \mathrm{C}$ where the temperature decayed exponentially with respect to time (fig. 2). The threshold level of the $A E$ equipment was adjusted by running calibration experiments so that no $A E$ counts were evolved from oxidation of the substrate. The results which are reported here therefore measure AE processes which originate from the plasmaspray coating process. The $A E$ was measured as accumulative counts or count rate and both of these parameters were subsequently processed to reveal any trends dependent on temperature or coating process conditions.

\section{RESULTS}

\section{Accumulative Counts}

The nature of all $A E$ events during the complete thermal cycle is summarized in table I. Only general trends can be inferred from the accumulative count data. The major problem in comparing different samples by means of an accumulative count analys is is that these counts are summed up from different count rate distributions. Each of these distributions represent different cracking processes and these are confounded by analyzing only the total counts. The numerical value for the total number of counts generated during a thermal cycle does not indicate how temperature relates to $A E$ response. Curves of accumulative counts versus temperature have been used (ref. 2) to show which temperatures are critical for $A E$ activity.

Examination of heating counts. - Two of the duplex coated component specimens (samples 6 and 8 ) exhibited a significantly greater $A E$ contribution on the first heating cycle compared to the $A E$ activity on subsequent cycles. 
The $A E$ generated during heating after the first cycle contributed only about 3 percent of the total counts. It should be noted that the replicates behaved differently.

Three of the single component specimens (samples 2, 3, and 4) exhibited a large proportion of counts during heating. Generally these specimens were observed to have falled at the end of the first thermal cycle and thus there is limited thermal cycling data.

Effect of thermal cycling. - The first cycle for a series of tests always exhibited the lowest accumulative counts. The duplex samples (both preheated and nonpreheated, cases $C$ and $D)$ produced fewer counts during cooling on the first cycle than the preheated single component coatings (case $B$ ). The second cooling cycle exhibited a factor from 7 to 2.7 times as many counts as the first cycle for coatings prepared with a bond coat (cases $C$ and $D$ ). There is limited thermal cycling data from the single component coatings (cases $A$ and B) because most of the samples falled after a single cycle. Fallure in most cases had progressed to the point that the coating could be removed as an integral cylinder of ceramic ( $\mathrm{fig} .3$ ). Specimens 4 (case B) and 5 (case C) did not completely detach from the substrate but exhibited edge cracks. In all instances a powder product from oxidation of the bond coat or substrate was also observed when the coating was removed. In some cases a blue-green scale adhered to the inside surface of the ceramic cylinder and this color is characteristic of a $\mathrm{Ni}-\mathrm{Cr}-\mathrm{Al}$ spinel.

\section{Count Rate Data}

Single component coatings. - Figure 4 shows the count rate data for the single component coatings (cases $A$ and $B$ ). Note that the temperature scale is drawn in the conventional manner so that it increases towards the right. However the experiment involved cooling of the specimen so thus, in these plots, time increases towards the origin. Acoustic emission is generated immediately upon. cooling from $1200^{\circ} \mathrm{C}$. This gradually decreases to a minimum at a temperature of about $800^{\circ} \mathrm{C}$. Acoustic emission signa's are again generated at lower temperatures and the count rate increases to a maximum at approximately $100^{\circ} \mathrm{C}$ before gradually decreasing to a minimum at temperatures of about $55^{\circ} \mathrm{C}$. For convenience this $A E$ behavior is termed the "systematic response regime." In all cases there are small random fluctuations in the signal about the systematic trend. However in many cases there are also large erratic signals superimposed on the AE response curves. This $A E$ behavior is referred to as the "stochastic response regime." These large count rates are thought to represent macrocracking processes such as interlamellar cracking or coating delamination because those samples which delaminated on the first cycle exhibited the stochastic response. They may also arise, from previously-formed cracks which interact by sifing in a haphazard and irregular fashion. The processes which give rise to the systematic and stochastic regimes occur at higher temperatures for the preheated YSZ coating. The gradual decrease in count rate at temperatures less than about $100^{\circ} \mathrm{C}$ will be discussed later.

Duplex component coatings (first cycle). - The duplex coating systems (cases $C$ and $D$ ) also exhibited the same general trends. Examination of the first cycle (figs. 5(a) and (d)) shows that these coatings had less $A E$ than 
the single component coatings which were examined above. The nonpreheated coatings (case $C$ ) did not exhibit the stochastic noise distribution which was observed for the single component coatings (cases $A$ and $B$ ). The nonpreheated coatings (case C) commenced AE activity at temperatures less than $600^{\circ} \mathrm{C}$ which may be compared to $1200^{\circ} \mathrm{C}$ for all the other coating systems.

The preheated duplex coatings (case D) displayed significant AE activity at temperatures greater than $1100^{\circ} \mathrm{C}$. These samples also displayed more systematic and stochastic activity below 500 $\mathrm{C}$ than the optimally sprayed duplex coating (case $C$ ).

Duplex component coatings (greater than one cycle). - The second thermal cycle (figs. 5(b) and (e)) was different from the initial cycle (figs. 5(a) and $(d))$. Both the systematic and stochastic distributions of $A E$ increased and this resulted in a greater accumulative count. On the third cycle there was a further increase in the stochastic behavior so that the continuous behavior was masked. It is difficult to discern real trends which may be associated with the initiation temperature of $A E$ because these temperatures are all grouped within the $500^{\circ}$ to $600^{\circ} \mathrm{C}$ band.

The continuous response regimes of cycles two and three contrast for both coating conditions. The third cycle exhibits higher count rates than cycle two; i.e., more cracking processes evolve at equivalent temperatures with increased thermal cycling. In the third cycle (figs. $5(c)$ and (f)) there is a transition in crack behavior to more cracking events of a stochastic nature. It is important to point out that the continuous regime was never completely absent from the $A E$ phenomena observed in this study.

\section{DISCUSSION}

The gain of the $A E$ instrument was adjusted so that there was no response, as indicated by $A E$ counts, from oxidation of the uncoated substrate. Therefore $A E$ is assumed to correspond to cracking processes which occur as a result of the plasma-spray deposition process. Thus higher count rates, such as are observed from the stochastic regime, can be related to macrocracking processes and this has been supported by the observation of delamination during the first cycle for cases $A$ and $B$. The precise nature of the phenomena which give rise to the systematic response is, at present, unclear. It might be expected that microcracking processes would produce this continuous AE trend. However it must be remembered that the systematic response was observed up until the seventh thermal cycle, at which point the coating was known to be detached from the substrate so that microcracking would not appreciably affect the $A E$ response. This does not mean that no microcracking occurs during these later stages of the experiment; but that other processes may contribute more to the AE response. For example oxidation products may spall or mechanically interact with each other, the substrate, or the coating to produce the systematic trend. These details can only be clarified by further experiments.

Regardless of the precise phenomena which gave rise to the systematic count rate distribution; these processes, whether they are microcracking, oxide spalling or interaction of the oxide products, are indicative of fallure processes occurring within the coating. It is also difficult to examine a 
single thermal cycle as a means of ascertaining the coating integrity. For example the systematic response of later cycles (for cases $C$ and $D$ ) should be reconciled with the stochastic response which becomes more predominant in the third cycle (figs. $5(c)$ and $(f)$ ). Thus there is evidence of macrocracking processes occurring throughout the entire period of experimentation. There is also a systematic AE response which is thought to be representative of microcracking processes, especlaliy in the early cycles, and oxide-related interaction for the later cycles.

Most $A E$ was generated on cooling of the coating which infers that coating failure occurs during this part of the cycle. This is in agreement with earlier work (ref. 7) which showed that coating fallure in furnace or burner rigs occurred as a result of thermal expansion mismatch stresses encountered on cooling. That study also showed that fallure was associated with bond coat oxidation and that fallure occurred by delamination cracking near the fnterface followed by surface cracking or spalling. oxidation of the bond coat is thought to alter the stress distribution within the ceramic and thus influences the fallure mechanism of the coating. For the present study coating fallure was observed either as cracking which originated from the free edge of the coating or as delamination such that the entire coating could be removed as a cylinder. Cracking is thought to originate from an edge because of high shear stresses at that location. Edge effect cracking has not been thoroughly investigated. However it has been observed (ref. 7) that cracking which is not associated with an edge signifies the early stages of delamination at the interface and this may be the case for the edge cracks found in this study.

The elastic energy from a single cracking event can be represented by a sinusoldal function with the amplitude decaying exponentially with time, i.e., the signal "rings down". Therefore the count rate parameter is proportional to the amplitude of the original signal. The count rate value will depend on the number of times that the ring down crosses the threshold voltage. With this in mind it can be considered that the systematic regime arises from events with simflarly shaped ring down responses. A larger count rate evolves as the temperature decreases because of an increase in the number of events or an increase in the size of the ring down count." In a similar manner it can be argued that the stochastic regime also derives from large changes in the shape of the initial ring down response. In this case it is more probable that a large increase in count rate represents a greater degree of macrocracking or crack interaction (with no crack growth) such as irregular silding. With these assumptions in mind the $A E$ activity may be qualitatively compared to the amplitude distribution analysis previously mentioned (ref. 3). A higher count rate during the stochastic regime, which was observed for the preheated coating system or from thermal cycling, signifies a different cracking mechanism or the same cracking mechanism occurring at a higher rate. This cracking is thought to occur at the interface between the substrate and coating since this was the observed locus of fallure. The AE signal shift from systematic to stochastic responses most probably represents a transition from microcracking or oxide interaction to macrocracking in localized regions.

A drop off in the count rate of the continuous regime with temperature is observed below about $100^{\circ} \mathrm{C}$. This is thought to be related to the exponentially decreasing cooling rate of the specimen at temperatures below $100^{\circ} \mathrm{C}$. While it would be expected that lower temperature would correspond to 
increased thermal expansion mismatch strain and hence more cracking, it should be remembered that the change in cooling rate is also decreasing with respect to time. The cracking processes depend on both the rate of temperature change and the absolute value of temperature. The rate of change in temperature becomes zero as the coating approaches room temperature. Therefore cracking, as indicated by $A E$, should cease (at least eventually) and this was observed as specimens were allowed to come to room temperature on cycle 7 .

A number of experimental conditions should be remembered. The heating and cooling rates of the specimen do not represent practical operating conditions of a thermal barrier coating. However faflure is still thought to occur on cooling in higher heat flux Mach 0.3 tests (ref. 7 ). At higher heat fluxes, such as those in an englne, the cooling mode of fallure is still likely to be important. Thus coating fallure, for the present case, results from thermal expansion mismatch stresses between the coating and substrate as well as any oxidation effects of the bond coat and/or substrate.

\section{CONCLUDING REMARKS}

Plasma-sprayed thermal barrier coatings have been subjected to thermal cycling tests with simultaneous $A E$ monitoring. The accumulative number of counts and the count rate data has been analyzed to establish how different processing conditions and coating systems can be differentiated in terms of fallure mechanisms.

Two different types of AE distributions can be observed by examining the count rate and these indicate two cracking processes. The systematic response distribution is thought to represent the progressive growth and interaction of microcracks (1.e., subcritical crack growth) and possibly the spalling and interaction of oxidation products. The number of these events increases with decreasing temperature and therefore the $A E$ count rate generation increases. At low temperatures the count rate decreases because of the exponentially decreasing cooling rate of the specimen. The stochastic count rate phenomenon was superimposed on the systematic response. These large count rates are presumed to evolve from macrocracking processes (1.e., critical crack growth). Thus macrocracking was observed to occur near the substrate-coating interface where stresses are greatest.

The processing conditions, coating system structure (single versus duplex) and the number of thermal cycles influenced the $A E$ response. The different cracking processes were distinguished by qualitative examination of the $A E$ count rate data. The accumulative number of counts on the heating portion of the thermal cycle were also analyzed to establish trends between coatings.

Several criticisms, or experimental improvements, can be offered in the light of these tests. The specimen geometry should permit 100 percent coverage of the plasma-sprayed coating system. In this manner AE events which arise from incomplete surface coverage, such as from edge effects, can be avoided. There is also the benefit that oxidative weight gains may be measured. Future tests shall control the furnace 'temperature gradient so that it is linear over the entire temperature range of experimentation. With a 
linear temperature gradient it w111 be possible to measure how the rate of temperature change with respect to time influences the $A E$ response and hence the cracking behavior.

This work has been exploratory with the aim of using AE methodology for the in situ examination of coatings during thermal experiments. It is anticipated that development of the method used for data analysis and the experimental techniques can lead to further critical experiments.

\section{REFERENCES}

1. Shankar, R. N., Berndt, C. C., Herman, H., and Rangaswamy, S.: Am. Ceram. Soc. Bul1. 62 (5) 614 (1983).

2. Berndt, C. C., and Herman, H.: Thin Soltd Films 108427 (1983).

3. Almond, D., Moghis 1, M., and Reiter, H.: Thin Solid Films. 108439 (1983).

4. Berndt, C. C.: Presented at the 29th ASME Inter. Gas Turbine Conf. and Exhibit, June $3-7,1984$, Amsterdam, The Netherlands (to be published).

5. Shankar, R. N., Berndt, C. C., and Herman, H.: in Advances in Materials Characterization, edited by $D$. R. Rossington, R. A. Condrate, and R. L. Snyder, (Plenum, New York, 1983), Pp. 473 to 490 .

6. Wadley, H. N. G., Scruby, C. B., and Speake, J. H.: Int. Met. Rev. 25(2) 41 (1980).

7. Miller, R. A., and Lowe11, C. E.: Thin Solid Films. 95265 (1982). 
TABLE I. - ACCUMULATIVE ACOUSTIC EMISSION OF THERMALLY CYCLED COATINGS

\begin{tabular}{|c|c|c|c|c|}
\hline \multirow{2}{*}{$\begin{array}{l}\text { Substrate } \\
\text { treatment } \\
\text { and coatinga }\end{array}$} & \multirow{2}{*}{$\begin{array}{l}\text { Specimen } \\
\text { designation } \\
\text { numberb }\end{array}$} & \multicolumn{2}{|c|}{ Cyclic accumulative counts } & \multirow{2}{*}{$\begin{array}{l}\text { Heating counts } \\
\text { as a percentage } \\
\text { of total counts }\end{array}$} \\
\hline & & Heating & Cooling & \\
\hline A. YSZ & $\begin{array}{l}1.1 \\
1.2 \\
2.1\end{array}$ & $\begin{array}{r}55 \\
55 \\
338\end{array}$ & $\begin{array}{r}7596 \\
10594 \\
3924\end{array}$ & $\begin{array}{l}0.7 \\
0.5 \\
7.9\end{array}$ \\
\hline B. PreheatC + YSZ & $\begin{array}{l}3.1 \\
4.1\end{array}$ & $\begin{array}{r}610 \\
1599\end{array}$ & $\begin{array}{l}2454 \\
4486\end{array}$ & $\begin{array}{l}19.9 \\
26.3\end{array}$ \\
\hline . & $\begin{array}{l}5.1 \\
5.2 \\
5.3 \\
5.4 \\
5.5 \\
5.6 \\
5.7 \\
\\
6.1 \\
6.2 \\
6.3 \\
6.4 \\
6.5 \\
6.6 \\
6.7\end{array}$ & $\begin{array}{r}0 \\
310 \\
154 \\
178 \\
172 \\
207 . \\
206 \\
\\
537 \\
184 \\
191 \\
200 \\
141 \\
99 \\
255\end{array}$ & $\begin{array}{r}2000 \\
14059 \\
11487 \\
10433 \\
14558 \\
12572 \\
8628 \\
\\
1333 \\
8591 \\
12728 \\
7855 \\
4787 \\
13626 \\
23923\end{array}$ & $\begin{array}{r}0 \\
2.2 \\
1.3 \\
1.7 \\
1.2 \\
1.6 \\
2.3 \\
28.7 \\
2.1 \\
1.5 \\
2.5 \\
2.9 \\
0.7 \\
1.1\end{array}$ \\
\hline D. Preheat $\mathrm{C}+$ bond coat + YSZ & $\begin{array}{l}7.1 \\
7.2 \\
7.3 \\
7.4 \\
7.5 \\
7.6 \\
7.7 \\
8.1 \\
8.2\end{array}$ & $\begin{array}{r}0 \\
100 \\
224 \\
227 \\
246 \\
301 \\
274 \\
\\
196 \\
208\end{array}$ & $\begin{array}{r}3846 \\
10478 \\
10116 \\
12347 \\
12573 \\
15566 \\
11605 \\
\\
2720 \\
9661\end{array}$ & $\begin{array}{l}0 \\
1.0 \\
2.2 \\
1.8 \\
1.9 \\
1.9 \\
2.3 \\
6.7 \\
2.1\end{array}$ \\
\hline
\end{tabular}

aysz refers to the yttria-stabilized ceramic coating.

b The last number of the specimen designation refers to the thermal cycle.

${ }^{c}$ The precise details of substrate preheat are not known (see the text). 


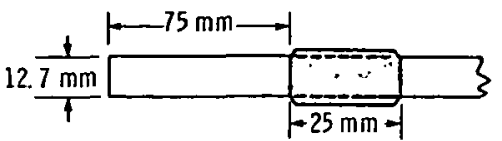

Figure 1. - Schematic of coating deposited onto substate.

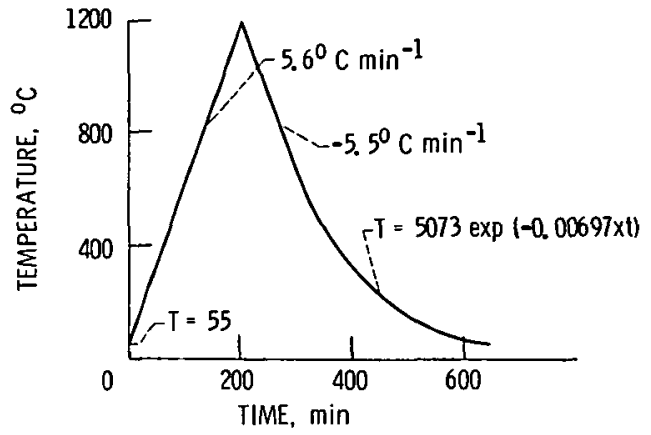

Figure 2. - Thermal history of specimen during a typical thermal cycle.

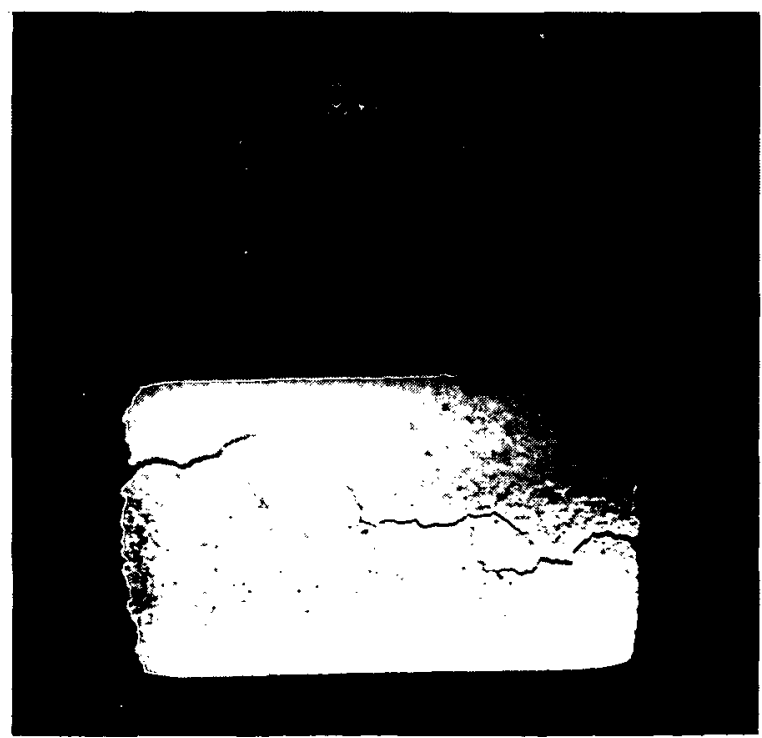

Figure 3. - Optical photograph of coating cylinder removed from the substrate. The outside surface of the coating is visible. 

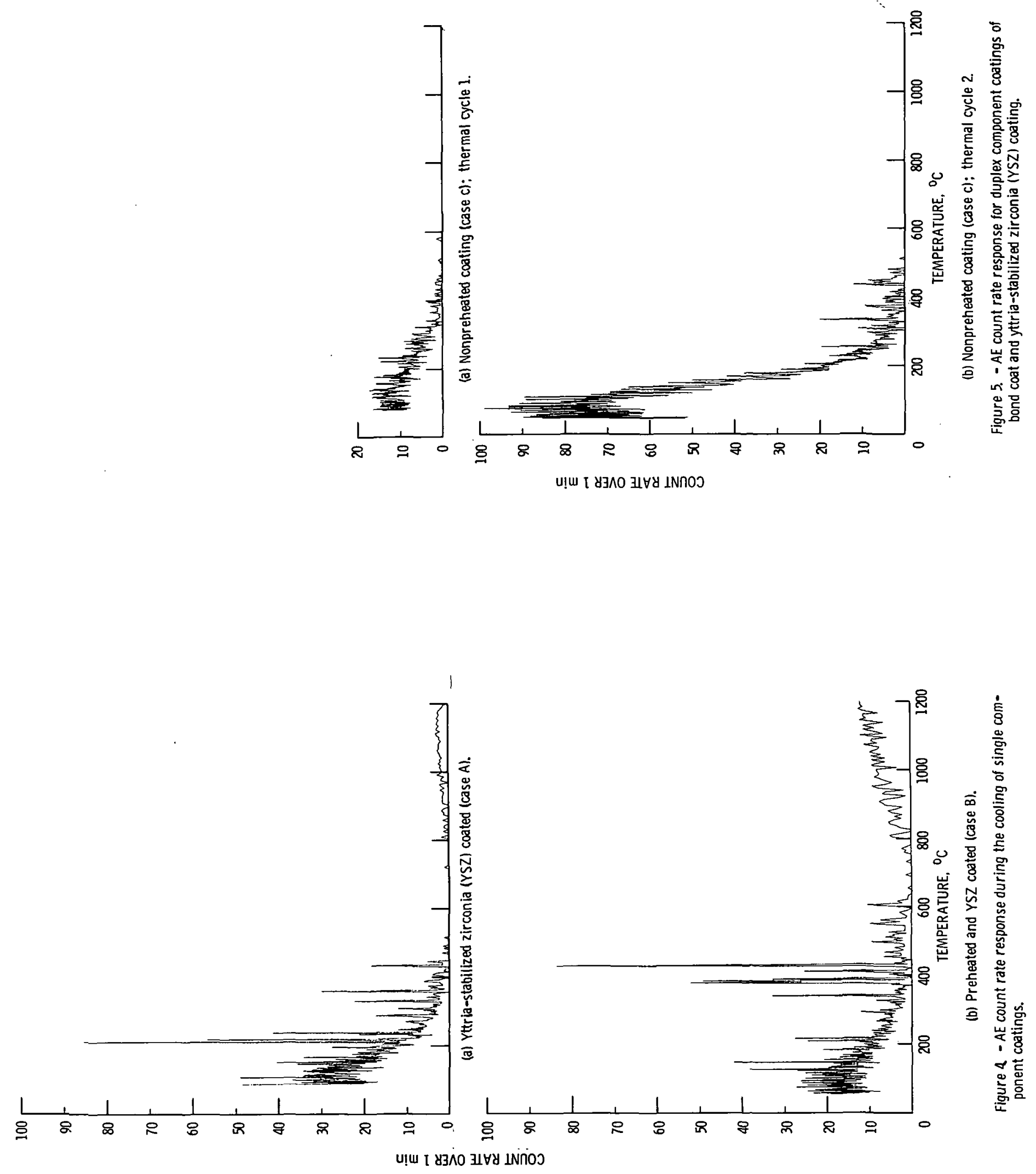

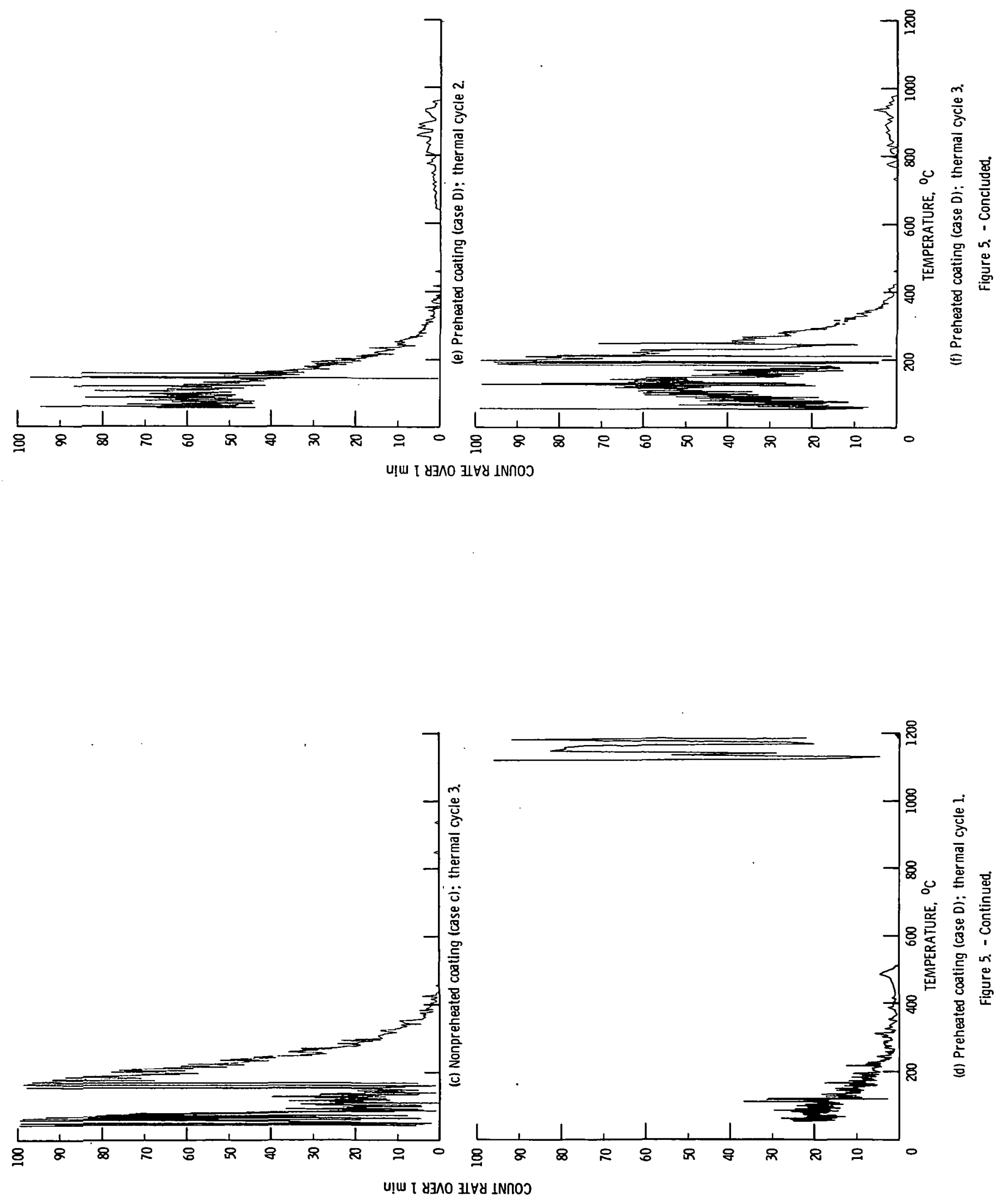


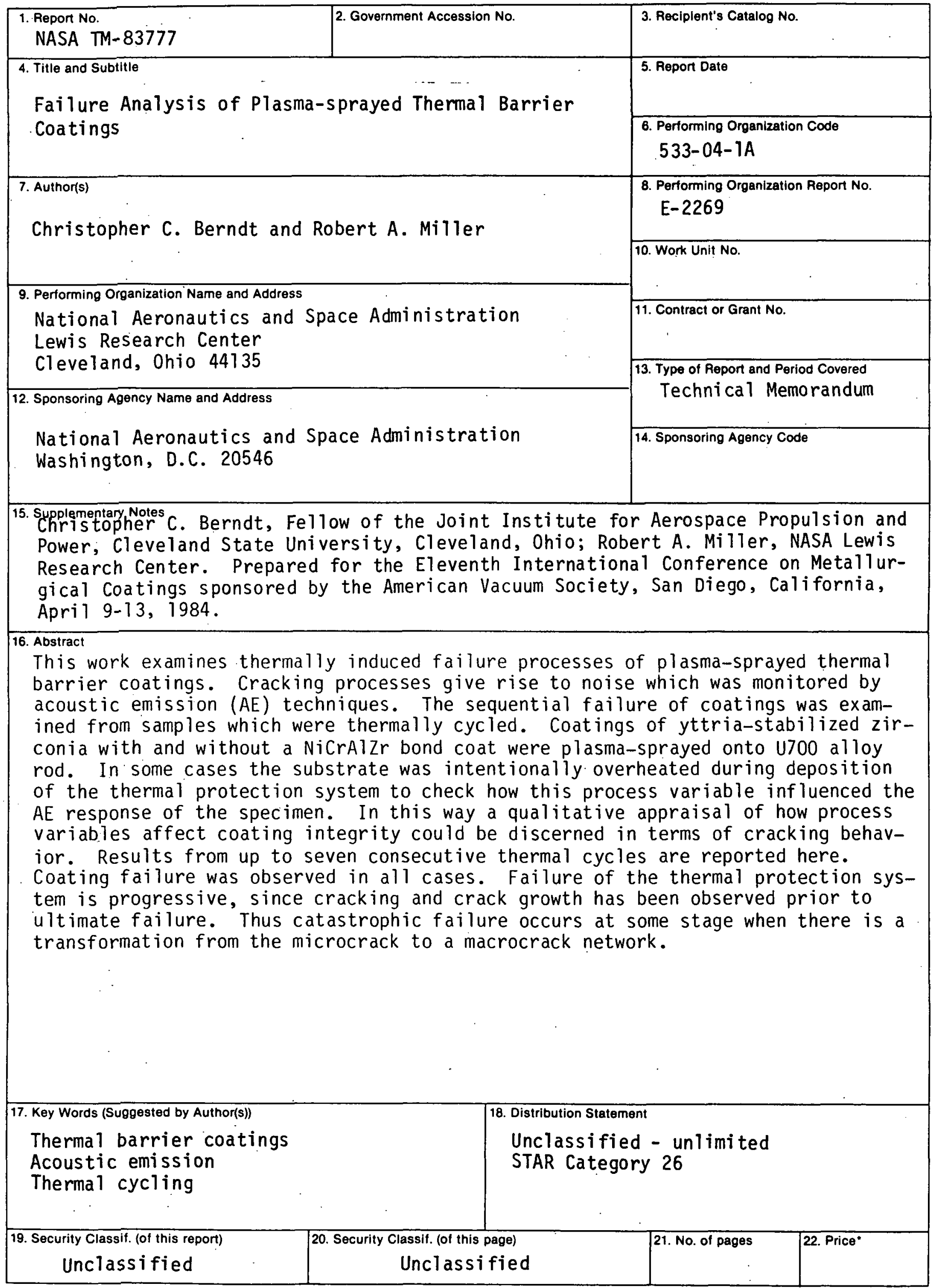

"For sale by the National Technical Information Service, Springfield, Virginia 22161 
National Aeronautics and Space Administration

Washington, D.C.

20546

Official Business

Penaliy for Private Use, $\$ 300$

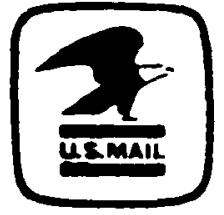

Postege and Fees Paid National Aeronautics and Sosce Administration NASA-451 